\title{
Air Path Estimation for a Turbocharged SI Engine with Variable Valve Timing
}

\author{
Thomas Leroy, Jonathan Chauvin, Guénaël Le Solliec and Gilles Corde
}

\begin{abstract}
In the context of increasingly stringent pollution standards, engine pollutant emission reduction is a great challenge for spark ignition (SI) engines. The very narrow operating zone of the three-way catalyst necessitates a good control of the air/fuel equivalence ratio and therefore a good estimation of the aspirated air mass. We consider in this study a turbocharged SI engine equipped with variable valve timing actuators (VVT). This device acts as a disturbance by impacting on the air mass flow through the inlet valves. This impact can be estimated from real-time measurement. Two observers of the aspirated air mass are then proposed in this paper. After proving convergence in the two cases, we carry out comparisons based on simulation results.
\end{abstract}

\section{INTRODUCTION}

On spark ignited (SI) engines, three-way catalysts (TWC) are used to reduce the pollutants $\left(\mathrm{CO}, \mathrm{HC}\right.$ and $\left.\mathrm{NO}_{x}\right)$ created by the combustion. However, the TWC can convert efficiently the three species to water and carbon dioxide for a very narrow air/fuel ratio $(\lambda)$ area (see Figure 1). Thus, it is important to keep the air/fuel ratio near the stoichiometric value $(\lambda=1)$. The air/fuel ratio is the ratio of air mass and fuel mass in the cylinder when the valves are closed, it is defined by $\lambda=\frac{1}{14.6} \frac{M_{a i r}}{M_{\text {fuel }}}$. The key to reduce efficiently SI

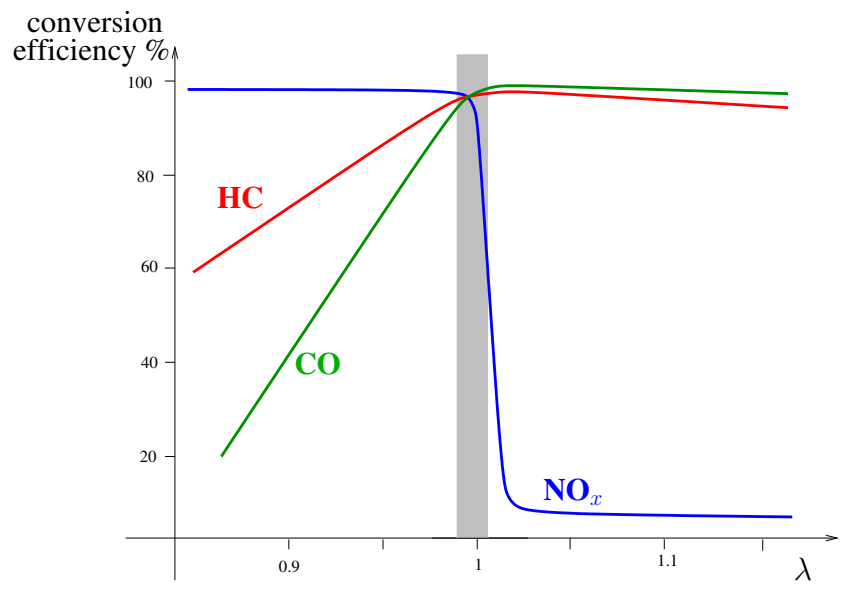

Fig. 1. Catalytic converter efficiency

engine pollution is then to make an accurate control of the air/fuel ratio. The air mass in the cylinder is estimated to calculate the injected fuel quantity so that the air/fuel ratio is balanced to the stoichiometric value.

T. Leroy (corresponding author), J. Chauvin, G. Le Solliec and G. Corde are with the Department of Engine Control in Institut Français du Pétrole, 1 et 4 Avenue de Bois Préau, 92852 Rueil Malmaison, France. thomas. leroydifp.fr.
On a classical turbocharged SI engine, the volumetric efficiency is used to estimate the air mass into the cylinder. Usually, the values of the volumetric efficiency are calibrated on the engine under steady state running conditions and ambient conditions (see [4], [1], [5], [6] for example). It is a nonlinear function of the engine speed and load. This information gives a feedforward term for the fuel injection $\left(M_{\text {fuel }}^{F F}=\frac{1}{14.6} M_{\text {air }}\right)$ which is completed by a feedback information gave by a PI controller based on the measurement from an oxygen sensor on the exhaust tailpipe.

Nowadays, downsizing (reduction of the engine size) appears as a major way of improving fuel consumption of SI engines by reducing the pumping losses at part load. To compensate the loss in the power output, turbochargers are used to increase the power of the engine. Variable Valve Timing (VVT) technology is also used to improve combustion efficiency and reduce $\mathrm{NO}_{x}$ emissions. See [12] for a thorough discussion on downsizing. The position of the wastegate and the variation of VVT change the exhaust manifold pressure and the residual gas mass trapped inside the cylinder at intake valve closing. It causes a change of the volumetric efficiency which is the main variable for fuel control feedforward. Figure 2 shows the influence of VVT on the volumetric efficiency at constant engine speed.

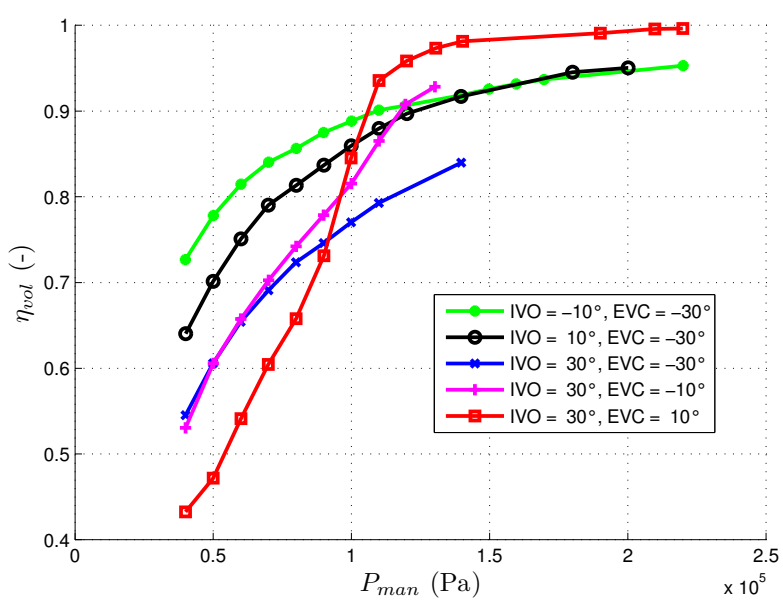

Fig. 2. Experimental volumetric efficiency, for different positions of VVT, as a function of the intake manifold pressure at constant engine speed $(2000 \mathrm{rpm})$. IVO and EVC respectively define the Intake Valve Opening timing and the Exhaust Valve Closure timing to the TDC position angle.

Constructing a map of the volumetric efficiency as a function of engine speed, intake pressure and VVT positions 
is a time-consuming and expensive process. Yet, observers can be used to solve an input estimation problem (see [13] for a global overview) and to estimate the trapped air mass in the cylinder. Volumetric efficiency modelling and determination by the measurement of the intake manifold air flow, the manifold air pressure and temperature has been addressed previously in the literature (see [2], [5], [3], [7]). These approaches lead to an observer relying on a mean-value model of the intake flow (at the TDC time-scale).

The contribution of the paper is the design of two air mass observers. Both are validated theoretically and in simulation. The first one is based on mass balance and an isothermal assumption (variations of the temperature in the intake manifold are assumed very small). The second one considers an additional energy balance in the reference system. In both cases, the proposed technique relies only on commercial-line engine sensors.

The paper is organized as follows. In Section II, we present the reference model in the intake manifold. In Section III, we propose an observer that updates a correcting term in the steady state law for the aspirated flow, neglecting temperature dynamics. This approach follows several ideas proposed in [2], [13], [3]. It allows to take into account variables that are not considered in the data fit (exhaust pressure, exhaust temperature, ...). A convergence proof is also given for that observer. In Section IV, we present a new observer taking into account intake manifold temperature dynamics. As previously, a convergence proof is given for that observer. Experimental results and quantitative comparisons in terms of performance, robustness and numerical efficiency are reported in Section V. We finally conclude and give future directions in Section VI.

\section{INTAKE MODELING}

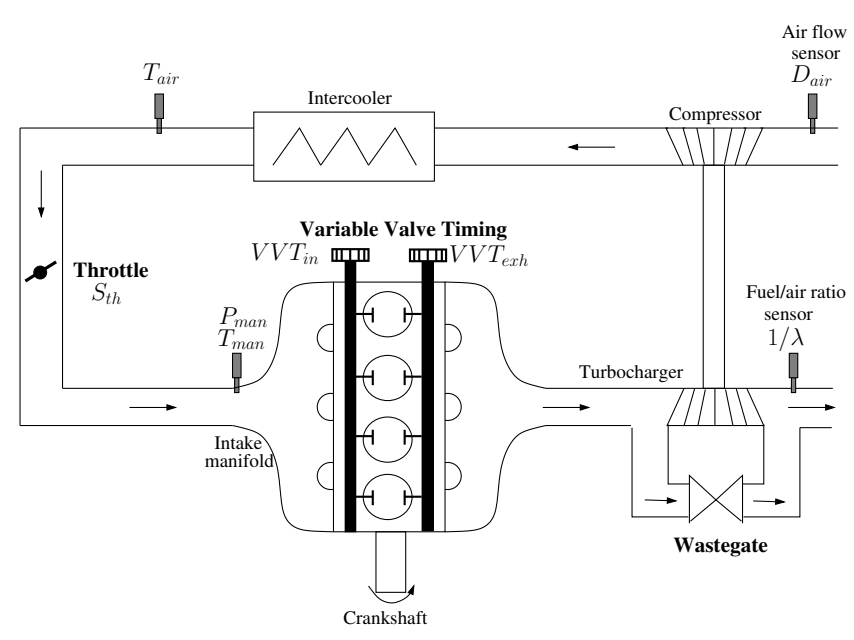

Fig. 3. Engine scheme

\section{A. Mass and energetics balance in the intake manifold}

Notations are given in Table I. We consider the intake manifold as a fixed volume for which the thermodynamic states (pressures, temperatures, composition) are assumed to be the same over the entire volume. The mass balance in the volume gives

$$
\dot{P}_{\text {man }}=\frac{\gamma R}{V_{\text {man }}}\left[D_{a i r} T_{a i r}-D_{a s p} T_{m a n}\right]
$$

and the energetics balance gives

$$
\begin{aligned}
\dot{T}_{\text {man }}= & \frac{R T_{\operatorname{man}}}{P_{\operatorname{man}} V_{\operatorname{man}}}\left[D_{a i r}\left(\gamma T_{a i r}-T_{\text {man }}\right)\right. \\
& \left.-D_{a s p}(\gamma-1) T_{m a n}\right]
\end{aligned}
$$

TABLE I

NOMENCLATURE

\begin{tabular}{|l|l|l|}
\hline Symbol & Description & Unit \\
\hline$D_{\text {air }}$ & Manifold air flow & $\mathrm{kg} \cdot \mathrm{s}^{-1}$ \\
$D_{\text {asp }}$ & Aspirated air flow into the cylin- & $\mathrm{kg} \cdot \mathrm{s}^{-1}$ \\
& ders & \\
$M_{\text {asp }}$ & Air mass trapped into the cylinders & $\mathrm{kg}$ \\
$N_{e}$ & Engine speed & $\mathrm{rpm}$ \\
$P_{\text {man }}$ & Pressure in the intake manifold & $\mathrm{Pa}$ \\
$R$ & Ideal gas constant & $\mathrm{J} \cdot \mathrm{kg}^{-1} \cdot \mathrm{K}^{-1}$ \\
$T_{\text {air }}$ & Fresh air temperature & $\mathrm{K}$ \\
$T_{\text {man }}$ & Temperature in the intake manifold & $\mathrm{K}$ \\
$V_{\text {cyl }}$ & Cylinders volume & $\mathrm{m}^{3}$ \\
$V_{\text {man }}$ & Intake manifold volume & $\mathrm{m}^{3}$ \\
$\delta \eta$ & Volumetric efficiency error & - \\
$\eta_{\text {map }}\left(N_{e}, P_{\text {man }}\right)$ & $\begin{array}{l}\text { Experimental } \\
\text { efficiency, at steady state }\end{array}$ \\
$\gamma$ & Specific heats ratio in the intake & - \\
& manifold & $\mathrm{K}$ \\
\hline
\end{tabular}

\section{B. Mean model of the aspirated flow}

In spite of the complexity of the fluid dynamics phenomena occurring during a transient (due to fast opening or closing the throttle), the conventional volumetric efficiency $\eta_{\text {map }}$ (function of the engine working point), identified during steady-state conditions, is used to describe carefully the inlet air mass flow. The speed density gives an accurate description of the air mass flow through inlet valves [9].

$$
D_{a s p}=\left(\eta_{\text {map }}\left(N_{e}, P_{\text {man }}\right)+\delta \eta\right) \frac{V_{c y l}}{R T_{\text {man }}} \frac{N_{e}}{120} P_{\text {man }}
$$

The term $\eta_{\text {map }}\left(N_{e}, P_{\text {man }}\right)$ represents a highly nonlinear function of the engine speed and intake manifold pressure. It can only be calculated via experimentation. $\delta \eta$ represents the second part of the volumetric efficiency that corresponds to small variations of exhaust conditions or VVT for example.

\section{Reference model}

Considering the balance equations (1) and (2) and the definition of the aspirated air flow (3), the reference model of the intake manifold is given by

$$
\left\{\begin{aligned}
\dot{P}_{\text {man }}= & \frac{\gamma R}{V_{\text {man }}}\left[D_{a i r} T_{\text {air }}\right. \\
& \left.-\left(\eta_{\text {map }}\left(N_{e}, P_{\text {man }}\right)+\delta \eta\right) \frac{V_{c y l}}{R} \frac{N_{e}}{120} P_{\text {man }}\right] \\
\dot{T}_{\text {man }}= & \frac{R T_{\text {man }}}{P_{\text {man }} V_{\text {man }}}\left[D_{a i r}\left(\gamma T_{a i r}-T_{m a n}\right)\right. \\
& \left.-\left(\eta_{\text {map }}\left(N_{e}, P_{\text {man }}\right)+\delta \eta\right) \frac{V_{c y l}}{R} \frac{N_{e}}{120} P_{\text {man }}(\gamma-1)\right]
\end{aligned}\right.
$$




\section{ISOTHERMAL CASE}

In this part, we assume that variations of temperature in equations (4) are small (as in [8] and [2] for example), i.e. $\dot{T}_{\text {man }}=0$. This leads to the following equation

$$
\begin{gathered}
D_{\text {air }}\left(\gamma T_{\text {air }}-T_{\text {man }}\right) \\
-\left(\eta_{\text {map }}\left(N_{e}, P_{\text {man }}\right)+\delta \eta\right) \frac{V_{c y l}}{R} \frac{N_{e}}{120} P_{\text {man }}(\gamma-1)=0
\end{gathered}
$$

Using the condition (5) into (4), the dynamics model of the intake manifold becomes

$$
\begin{aligned}
\dot{P}_{\text {man }}= & \frac{R T_{\operatorname{man}}}{V_{\text {man }}}\left[D_{\text {air }}\right. \\
& \left.\left.-\left(\eta_{\text {map }}\left(N_{e}, P_{\text {man }}\right)+\delta \eta\right) \frac{V_{c y l}}{R T_{\text {man }}} \frac{N_{e}}{120} P_{\text {man }}\right)\right]
\end{aligned}
$$

\section{A. Reference model}

Let $x=\left[\begin{array}{ll}P_{\text {man }} & \delta \eta\end{array}\right]^{T} \in \mathbb{R}^{2}$ be the state and $y=$ $P_{\text {man }}$ the measurement. We note $\alpha_{\text {int }}=\frac{R T_{\operatorname{man}}}{V_{\operatorname{man}}}$ and $\beta_{\text {int }}=$ $\frac{V_{c y l}}{R T_{\text {man }}} \frac{N_{e}}{120}$. Assuming a small variation on $\delta \eta$, we have

$$
\left\{\begin{array}{l}
\dot{x}_{1}=\alpha_{\text {int }}\left[D_{\text {air }}-\left(\eta_{\text {map }}\left(N_{e}, x_{1}\right)+x_{2}\right) \beta_{\text {int }} x_{1}\right] \\
\dot{x}_{2}=0 \\
y_{1}=x_{1}
\end{array}\right.
$$

Notations are summarized in Table II.

TABLE II

VARIABLES DESCRIPTION - ISOTHERMAL OBSERVER

\begin{tabular}{|c|c||c|c|}
\hline Variable & Symbol & Variable & Expression \\
\hline$x_{1}$ & $P_{\operatorname{man}}$ & $\alpha_{i n t}$ & $\frac{R T_{\operatorname{man}}}{V_{\operatorname{man}}}$ \\
$x_{2}$ & $\delta \eta$ & $\beta_{i n t}$ & $\frac{V_{c y l}}{R T_{\operatorname{man}}} \frac{N_{e}}{120}$ \\
$y$ & $P_{\operatorname{man}}$ & & \\
\hline
\end{tabular}

\section{B. Observer design}

We define a nonlinear observer. The observer dynamics are

$$
\left\{\begin{aligned}
\dot{\hat{x}}_{1}= & \alpha_{\text {int }}\left[D_{\text {air }}-\left(\eta_{\text {map }}\left(N_{e}, y\right)+\hat{x}_{2}\right) \beta_{i n t} \hat{x}_{1}\right] \\
& -L_{1}\left(\hat{x}_{1}-y\right) \\
\dot{\hat{x}}_{2}= & L_{2}\left(\hat{x}_{1}-y\right)
\end{aligned}\right.
$$

where $\left(L_{1}, L_{2}\right) \in\left(\mathbb{R}^{+} \backslash\{0\}\right)^{2}$. The state-error is $\tilde{x}=x-\hat{x}$, we also give the error dynamics

$$
\left\{\begin{aligned}
\dot{\tilde{x}}_{1}= & \alpha_{\text {int }} \beta_{\text {int }}\left[-\left(\eta_{\text {map }}\left(N_{e}, y\right)+x_{2}\right) \tilde{x}_{1}-\hat{x}_{1} \tilde{x}_{2}\right] \\
& -L_{1} \tilde{x}_{1} \\
\dot{\tilde{x}}_{2}= & L_{2} \tilde{x}_{1}
\end{aligned}\right.
$$

Tuning parameters are chosen as follows

$$
\left\{\begin{array}{l}
L_{1}=\alpha_{\text {int }} \beta_{\text {int }} l_{1} \\
L_{2}=\alpha_{\text {int }} \beta_{\text {int }} \hat{x}_{1} l_{2}
\end{array}\right.
$$

where $l_{1}$ and $l_{2}$ are positive constants. With this choice, the error system writes

$$
\left\{\begin{array}{l}
\dot{\tilde{x}}_{1}=\alpha_{i n t} \beta_{\text {int }}\left[-\left(\eta_{\text {map }}\left(N_{e}, y\right)+x_{2}+l_{1}\right) \tilde{x}_{1}-\hat{x}_{1} \tilde{x}_{2}\right] \\
\dot{\tilde{x}}_{2}=\alpha_{\text {int }} \beta_{\text {int }} \hat{x}_{1} l_{2} \tilde{x}_{1}
\end{array}\right.
$$

\section{Convergence analysis}

To prove convergence of the observer state $\hat{x}$ of system (8) to the state $x$ of the reference system (7), we exhibit a Lyapunov function and use LaSalle's theorem.

\section{LYAPUNOV FUNCTION CANDIDATE}

Convergence of (9) toward $\{0\}$ can be achieved through a Lyapunov stability analysis. A Lyapunov function candidate is

$$
V(\tilde{x})=\frac{1}{2 \alpha_{i n t} \beta_{\text {int }}}\left(\tilde{x}_{1}^{2}+\frac{1}{l_{2}} \tilde{x}_{2}^{2}\right)
$$

Differentiation leads to

$$
\begin{aligned}
\dot{V}(\tilde{x}) & =\frac{1}{\alpha_{i n t} \beta_{\text {int }}}\left(\tilde{x}_{1} \dot{\tilde{x}}_{1}+\frac{1}{l_{2}} \tilde{x}_{2} \dot{\tilde{x}}_{2}\right) \\
& =-\left(\eta_{\text {map }}\left(N_{e}, y\right)+l_{1}+x_{2}\right) \tilde{x}_{1}^{2} \\
& \leq-l_{1} \tilde{x}_{1}^{2}
\end{aligned}
$$

because $\eta_{\text {map }}\left(N_{e}, y\right)+x_{2}>0$. In summary, $V(0)=0$ and $\forall \tilde{x} \in(\mathbb{R} \backslash\{0\})^{2}, V(\tilde{x})>0$ and $\dot{V}(\tilde{x}) \leq 0$. From Lyapunov theorem (see [10] Theorem 4.1), the next lemma holds

Lemma 1: The function $V$ defined by (10) is a Lyapunov function for the error-state system (9).

\section{APPLiCATION OF LASALLE'S THEOREM}

Let $\Omega_{r}=\left\{\tilde{x}_{f} \in \mathbb{R}^{2} / V\left(\tilde{x}_{f}\right)<r\right\} \subset \mathbb{R}^{2}$. It is a compact set positively invariant with respect to the error dynamics (9). Let $V$ be a continuously differentiable function such that $\dot{V}\left(\tilde{x}_{f}\right) \leq 0$ in $\Omega_{r}$. Let $I_{f}$ be the largest invariant set in $\left\{\tilde{x}_{f} \in \Omega_{r} / \dot{V}\left(\tilde{x}_{f}\right)=0\right\}$. From LaSalle's theorem (see [10] Theorem 4.4), every solution starting in $\Omega_{r}$ approches $I_{f}$ as $t \rightarrow \infty$.

\section{CHARACTERIZATION OF THE INVARIANT SET $I_{f}$}

We first characterize $\left\{\tilde{x}_{f} \in \Omega_{r} / \dot{V}\left(\tilde{x}_{f}\right)=0\right\}$ and then $I_{f}$. First,

$$
\tilde{x}_{f} \in\left\{\tilde{x}_{f} \in \Omega_{r} / \dot{V}\left(\tilde{x}_{f}\right)=0\right\} \Leftrightarrow \tilde{x}_{1 f}^{2}=0
$$

because the term $\eta_{\text {map }}\left(N_{e}, y\right)+l_{1}+x_{2}$ is positively bounded. Thus from LaSalle's theorem, $I_{f}$ is the largest invariant set in $\left\{\tilde{x}_{f} \in \Omega_{r} / \dot{V}\left(\tilde{x}_{f}\right)=0\right\}$. $I_{f}$ writes

$$
I_{f}=\left\{\left[\begin{array}{ll}
0 & \tilde{x}_{2 f}
\end{array}\right]^{T} \in \mathbb{R}^{2} /-\alpha_{i n t} \beta_{i n t} \hat{x}_{1} \tilde{x}_{2 f}=0\right\}
$$

Therefore, the set $I_{f}$ is reduced to $\{0\}$. Then $\{0\}$ is asymptotically stable for the error dynamics (9) and the following results hold

Lemma 2: The largest set in $\Omega_{r}=\left\{\tilde{x}_{f} \in \mathbb{R}^{2} / V\left(\tilde{x}_{f}\right)<\right.$ $r\} \subset \mathbb{R}^{2}$ invariant by the dynamics of the system (9), where the function $V$ is defined in (10), is the null space.

Proposition 1: The observer defined in equation (8) converges towards the reference model (7).

\section{Adiabatic case}

In this part, we don't neglect the temperature dynamics. Therefore, we consider the system (4). 


\section{A. Reference model}

Let $x=\left[\begin{array}{llll}P_{\text {man }} & T_{\text {man }} & \delta \eta & T_{\text {air }}\end{array}\right]^{T} \in \mathbb{R}^{4}$ be the state and $y=\left[\begin{array}{ll}P_{\text {man }} & T_{\text {man }}\end{array}\right]^{T}$ the mesurement. We note $\varphi_{i n t}=\frac{R}{V_{\operatorname{man}}}$ and $\xi_{\text {int }}=\frac{1}{R} V_{c y l} \frac{N_{e}}{120}$. Assuming small variations on $\delta \eta$ and $T_{a i r}$, the reference dynamics are

$$
\left\{\begin{aligned}
\dot{x}_{1}= & \gamma \varphi_{\text {int }}\left[D_{\text {air }} x_{4}-\left(\eta_{\text {map }}\left(N_{e}, x_{1}\right)+x_{3}\right) \xi_{\text {int }} x_{1}\right] \\
\dot{x}_{2}= & \varphi_{\text {int }} \frac{x_{2}}{x_{1}}\left[D_{\text {air }}\left(\gamma x_{4}-x_{2}\right)\right. \\
& \left.-\left(\eta_{\text {map }}\left(N_{e}, x_{1}\right)+x_{3}\right)(\gamma-1) \xi_{\text {int }} x_{1}\right] \\
\dot{x}_{3}= & 0 \\
\dot{x}_{4}= & 0 \\
y_{1}= & x_{1} \\
y_{2}= & x_{2}
\end{aligned}\right.
$$

Notations are summarized in Table III.

TABLE III

VARIABLES DESCRIPTION - ADIABATIC OBSERVER
\begin{tabular}{|c|c||c|c|}
\hline Variable & Symbol & Variable & Expression \\
\hline$x_{1}$ & $P_{\text {man }}$ & $\varphi_{\text {int }}$ & $\frac{R}{V_{\text {man }}}$ \\
$x_{2}$ & $T_{\text {man }}$ & $\xi_{\text {int }}$ & $\frac{1}{R} V_{c y l} \frac{N_{e}}{120}$ \\
$x_{3}$ & $\delta \eta$ & & \\
$x_{4}$ & $T_{\text {air }}$ & & \\
$y_{1}$ & $P_{\text {man }}$ & & \\
$y_{2}$ & $T_{\text {man }}$ & & \\
\hline
\end{tabular}

\section{B. Observer design}

We define a nonlinear observer. The observer dynamics are

$$
\left\{\begin{aligned}
\dot{\hat{x}}_{1}= & \gamma \varphi_{\text {int }}\left[D_{\text {air }} \hat{x}_{4}-\left(\eta_{\text {map }}\left(N_{e}, y_{1}\right)+\hat{x}_{3}\right) \xi_{\text {int }} \hat{x}_{1}\right] \\
& -L_{1}\left(\hat{x}_{1}-y_{1}\right) \\
\dot{\hat{x}}_{2}= & \varphi_{\text {int }} \frac{y_{2}}{y_{1}}\left[D_{\text {air }}\left(\gamma \hat{x}_{4}-\hat{x}_{2}\right)\right. \\
& \left.-\left(\eta_{\text {map }}\left(N_{e}, y_{1}\right)+\hat{x}_{3}\right)(\gamma-1) \xi_{\text {int }} \hat{x}_{1}\right] \\
& +L_{2,1}\left(\hat{x}_{1}-y_{1}\right)-L_{2,2}\left(\hat{x}_{2}-y_{2}\right) \\
\dot{\hat{x}}_{3}= & L_{3,1}\left(\hat{x}_{1}-y_{1}\right)+L_{3,2}\left(\hat{x}_{2}-y_{2}\right) \\
\dot{\hat{x}}_{4}= & -L_{4,1}\left(\hat{x}_{1}-y_{1}\right)-L_{4,2}\left(\hat{x}_{2}-y_{2}\right)
\end{aligned}\right.
$$

where $\left(L_{1}, L_{2,1}, L_{2,2}, L_{3,1}, L_{3,2}, L_{4,1}, L_{4,2}\right) \in\left(\mathbb{R}^{+} \backslash\{0\}\right)^{7}$. The state-error is $\tilde{x}=x-\hat{x}$, we also give the error dynamics

$$
\left\{\begin{aligned}
\dot{\tilde{x}}_{1}= & \gamma \varphi_{\text {int }}\left[D_{\text {air }} \tilde{x}_{4}-\eta_{\text {map }}\left(N_{e}, y_{1}\right) \xi_{\text {int }} \tilde{x}_{1}\right. \\
& \left.-\xi_{\text {int }}\left(\tilde{x}_{1} x_{3}+\hat{x}_{1} \tilde{x}_{3}\right)\right]-L_{1} \tilde{x}_{1} \\
\dot{\tilde{x}}_{2}= & \varphi_{\text {int }} \frac{y_{2}}{y_{1}}\left[D_{\text {air }}\left(\gamma \tilde{x}_{4}-\tilde{x}_{2}\right)\right. \\
& -\eta_{\text {map }}\left(N_{e}, y_{1}\right) \xi_{\text {int }}(\gamma-1) \tilde{x}_{1} \\
& \left.-\xi_{\text {int }}(\gamma-1)\left(\tilde{x}_{1} x_{3}+\hat{x}_{1} \tilde{x}_{3}\right)\right]+L_{2,1} \tilde{x}_{1}-L_{2,2} \tilde{x}_{2} \\
\dot{\tilde{x}}_{3}= & L_{3,1} \tilde{x}_{1}+L_{3,2} \tilde{x}_{2} \\
\dot{\tilde{x}}_{4}= & -L_{4,1} \tilde{x}_{1}-L_{4,2} \tilde{x}_{2}
\end{aligned}\right.
$$

Tuning parameters are chosen as follows

$$
\left\{\begin{aligned}
L_{1} & =\gamma \varphi_{\text {int }} \xi_{\text {int }}\left(l_{1}-\eta_{\text {map }}\left(N_{e}, y_{1}\right)\right) \\
L_{2,1} & =(\gamma-1) \varphi_{\text {int }} \xi_{\text {int }} \frac{y_{2}}{y_{1}}\left(\eta_{\text {map }}\left(N_{e}, y_{1}\right)+x_{3}\right) \\
L_{2,2} & =\varphi_{\text {int }} D_{\text {air }} \frac{y_{2}}{y_{1}} l_{2} \\
L_{3,1} & =\gamma \varphi_{\text {int }} \xi_{\text {int }} \hat{x}_{1} l_{3} \\
L_{3,2} & =(\gamma-1) \varphi_{\text {int }} \xi_{\text {int }} \frac{y_{2}}{y_{1}} \hat{x}_{1} l_{3} \\
L_{4,1} & =\gamma \varphi_{\text {int }} D_{\text {air }} l_{4} \\
L_{4,2} & =\gamma \varphi_{\text {int }} D_{\text {air }} \frac{y_{2}}{y_{1}} l_{4}
\end{aligned}\right.
$$

where $l_{1}, l_{2}, l_{3}$ and $l_{4}$ are positive constants. With this choice, the error system writes

$$
\left\{\begin{aligned}
\dot{\tilde{x}}_{1}= & \gamma \varphi_{\text {int }}\left[D_{\text {air }} \tilde{x}_{4}-\xi_{\text {int }}\left(l_{1}+x_{3}\right) \tilde{x}_{1}-\xi_{\text {int }} \hat{x}_{1} \tilde{x}_{3}\right] \\
\dot{\tilde{x}}_{2}= & \varphi_{\text {int }} \frac{y_{2}}{y_{1}}\left[D_{\text {air }} \gamma \tilde{x}_{4}-D_{\text {air }}\left(1+l_{2}\right) \tilde{x}_{2}\right. \\
& \left.-\xi_{\text {int }}(\gamma-1) \hat{x}_{1} \tilde{x}_{3}\right] \\
\dot{\tilde{x}}_{3}= & \gamma \varphi_{\text {int }} \xi_{\text {int }} \hat{x}_{1} l_{3} \tilde{x}_{1}+(\gamma-1) \varphi_{\text {int }} \xi_{\text {int }} \frac{y_{2}}{y_{1}} \hat{x}_{1} l_{3} \tilde{x}_{2} \\
\dot{\tilde{x}}_{4}= & -\gamma \varphi_{\text {int }} D_{\text {air }} l_{4} \tilde{x}_{1}-\gamma \varphi_{\text {int }} D_{\text {air }} \frac{y_{2}}{y_{1}} l_{4} \tilde{x}_{2}
\end{aligned}\right.
$$

\section{Convergence analysis}

To prove convergence of the observer state $\hat{x}$ of system (12) to the state $x$ of the reference system (11), we exhibit a Lyapunov function and use LaSalle's theorem.

\section{LYAPUNOV FUNCTION CANDIDATE}

Convergence of (13) toward $\{0\}$ can be achieved through a Lyapunov stability analysis. A Lyapunov function candidate is

$$
V(\tilde{x})=\frac{1}{2 \varphi_{\text {int }}}\left(\tilde{x}_{1}^{2}+\tilde{x}_{2}^{2}+\frac{1}{l_{3}} \tilde{x}_{3}^{2}+\frac{1}{l_{4}} \tilde{x}_{4}^{2}\right)
$$

Differentiation leads to

$$
\begin{aligned}
\dot{V}(\tilde{x}) & =\frac{1}{\varphi_{\text {int }}}\left(\tilde{x}_{1} \dot{\tilde{x}}_{1}+\tilde{x}_{2} \dot{\tilde{x}}_{2}+\frac{1}{l_{3}} \tilde{x}_{3} \dot{\tilde{x}}_{3}+\frac{1}{l_{4}} \tilde{x}_{4} \dot{\tilde{x}}_{4}\right) \\
& =-\gamma \xi_{\text {int }}\left(l_{1}+x_{3}\right) \tilde{x}_{1}^{2}-\frac{y_{2}}{y_{1}} D_{\text {air }}\left(1+l_{2}\right) \tilde{x}_{2}^{2} \\
& \leq 0
\end{aligned}
$$

because $l_{1}+x_{3}>0$ and $1+l_{2}>0$. In summary, $V(0)=$ 0 and $\forall \tilde{x} \in(\mathbb{R} \backslash\{0\})^{4}, V(\tilde{x})>0$ and $\dot{V}(\tilde{x}) \leq 0$. From Lyapunov theorem (see [10] Theorem 4.1), the next lemma holds

Lemma 3: The function $V$ defined by (14) is a Lyapunov function for the error-state system (13).

\section{APPLICATION OF LASALLE'S THEOREM}

Let $\Omega_{c}=\left\{\tilde{x}_{f} \in \mathbb{R}^{4} / V\left(\tilde{x}_{f}\right)<c\right\} \subset \mathbb{R}^{4}$. It is a compact set positively invariant with respect to the error dynamics (13). Let $V$ be a continuously differentiable function such that $\dot{V}\left(\tilde{x}_{f}\right) \leq 0$ in $\Omega_{c}$. Let $\Gamma_{f}$ be the largest invariant set in $\left\{\tilde{x}_{f} \in \Omega_{c} / \dot{V}\left(\tilde{x}_{f}\right)=0\right\}$. From LaSalle's theorem (see [10] Theorem 4.4), every solution starting in $\Omega_{c}$ approches $\Gamma_{f}$ as $t \rightarrow \infty$.

\section{CHARACTERIZATION OF THE INVARIANT SET $\Gamma_{f}$}

We first characterize $\left\{\tilde{x}_{f} \in \Omega_{c} / \dot{V}\left(\tilde{x}_{f}\right)=0\right\}$ and then $\Gamma_{f}$. First,

$$
\tilde{x}_{f} \in\left\{\tilde{x}_{f} \in \Omega_{c} / \dot{V}\left(\tilde{x}_{f}\right)=0\right\} \Leftrightarrow\left\{\begin{array}{l}
\tilde{x}_{1 f}=0 \\
\tilde{x}_{2 f}=0
\end{array}\right.
$$

because the terms $l_{1}+x_{3}$ and $1+l_{2}$ are positively bounded. Thus from LaSalle's theorem, $\Gamma_{f}$ is the largest invariant set in $\left\{\tilde{x}_{f} \in \Omega_{c} / \dot{V}\left(\tilde{x}_{f}\right)=0\right\} . \Gamma_{f}$ writes

$$
\Gamma_{f}=\left\{\left[\begin{array}{llll}
0 & 0 & \tilde{x}_{3 f} & \tilde{x}_{4 f}
\end{array}\right]^{T} \in \mathbb{R}^{4} / \Phi_{i n t}\left(\begin{array}{c}
\tilde{x}_{3 f} \\
\tilde{x}_{4 f}
\end{array}\right)=0\right\}
$$

with

$$
\Phi_{\text {int }}=\left(\begin{array}{cc}
-\gamma \varphi_{\text {int }} \xi_{\text {int }} \hat{x}_{1} & \gamma \varphi_{\text {int }} D_{\text {air }} \\
-\varphi_{\text {int }} \xi_{\text {int }} \frac{y_{2}}{y_{1}}(\gamma-1) \hat{x}_{1} & \gamma \varphi_{\text {int }} D_{\text {air }} \frac{y_{2}}{y_{1}}
\end{array}\right)
$$




$$
\operatorname{det}\left(\Phi_{\text {int }}\right)=-\gamma \varphi_{\text {int }}^{2} \xi_{\text {int }} D_{\text {air }} \frac{y_{2}}{y_{1}} \hat{x}_{1} \neq 0
$$

Therefore, the set $\Gamma_{f}$ is reduced to $\{0\}$. Then $\{0\}$ is asymptotically stable for the error dynamics (13) and the following results hold

Lemma 4: The largest set in $\Omega_{c}=\left\{\tilde{x}_{f} \in \mathbb{R}^{4} / V\left(\tilde{x}_{f}\right)<\right.$ c) $\subset \mathbb{R}^{4}$ invariant by the dynamics of the system (13), where the function $V$ is defined in (14), is the null space.

Proposition 2: The observer defined in equation (12) converges towards the reference model (11).

\section{Simulation AND ExPerimental RESUlts}

In order to test the two above observers, a series of experiments was performed on a high frequency engine model designed on the AMESim platform (see [11]). Test from vehicle data is also presented in the last part of the section.

The aim of the two observers is to estimate the air mass trapped into the cylinders, so let us introduce the variable $\hat{M}_{a s p}$ calculated from the air flow equation (3) :

$$
\hat{M}_{a s p}=\left(\eta_{\text {map }}\left(N_{e}, P_{\text {man }}\right)+\hat{\delta \eta}\right) \frac{V_{c y l}}{R T_{\text {man }}} \hat{P}_{\text {man }}
$$

where $\hat{P}_{\text {man }}$ and $\hat{\delta \eta}$ are the estimations given by the observers.

To test the observers, we first generate a torque demand and then a variation of VVT at constant intake pressure.

\section{A. Torque demand}

We test the observers on a $30-100 \mathrm{Nm}$ torque transient at $2000 \mathrm{rpm}$. The temperature dynamics is neglected to estimate the air mass in the isothermal observer. The air mass trajectory is reported in Figure 4. Here are represented the reference air mass given by the model $M_{a s p}$ ref, the masses given by the isothermal observer and the adiabatic observer and then the mass given by the map, $M_{a s p}^{m a p}$. This information is based on a two dimensional volumetric efficiency map function of intake pressure and engine speed at fixed VVT position. It is given by

$$
M_{\text {asp }}^{\text {map }}=\eta_{\text {map }}\left(N_{e}, P_{\text {man }}\right) \frac{V_{c y l}}{R T_{\text {man }}} P_{\text {man }}
$$

The term $\hat{\delta \eta}$ in the observers design is estimated to remove the static error given by the map (see Figure 5). If we use the map as a feedforward for fuel control, we would have a static error referring to the $M_{a s p}^{m a p}$ curve.

From a transient point of view, the estimation is pretty correct for the two observers. One can notice that convergence depends a lot on gain tuning. Besides, the adiabatic observer is harder to tune because of its many gains.

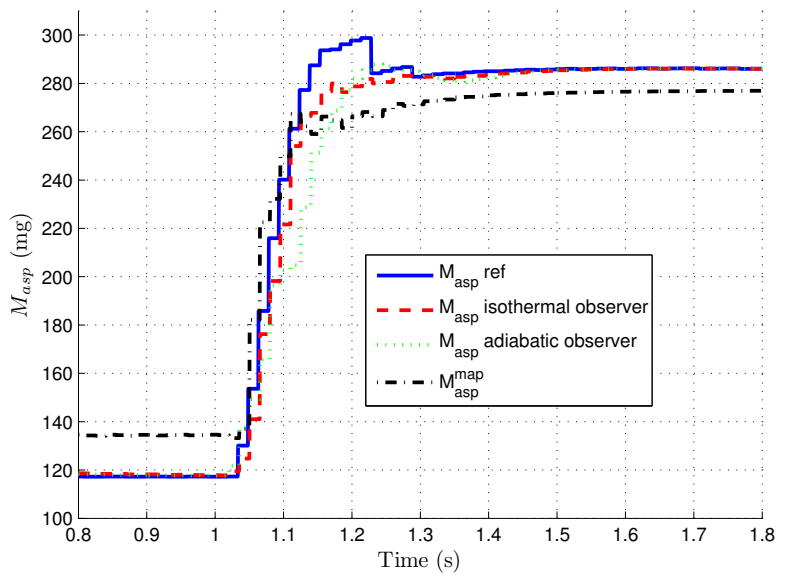

Fig. 4. Air mass aspirated during a 30-100 Nm torque transient at constant engine speed (2000 rpm).

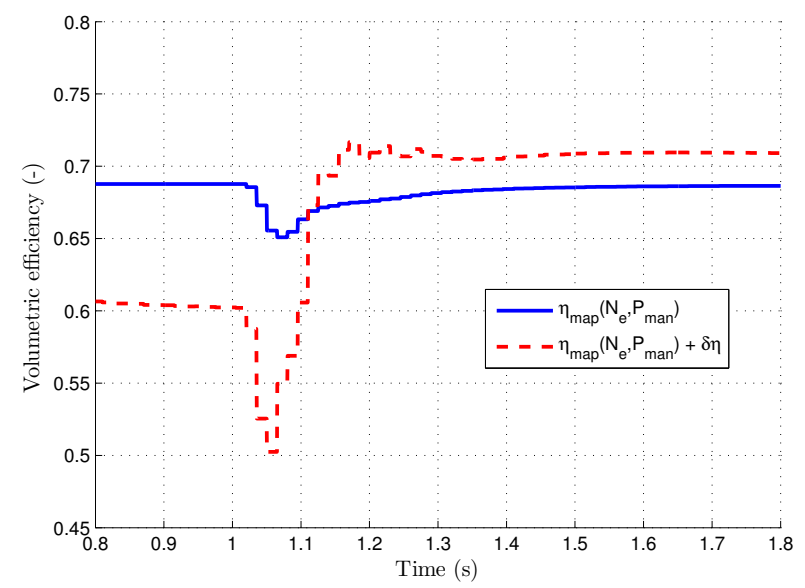

Fig. 5. Volumetric efficiency during a 30-100 Nm torque transient at $2000 \mathrm{rpm}$.

\section{B. Variation of VVT}

We now test the observers on VVT trajectory. A classical estimation of the air mass (function of intake pressure and engine speed) gives a wrong estimation when VVT move. Actually, it changes the composition of the mixture in the cylinder allowing an internal burned gas recirculation. To test the observers on this type of situation, let us change the burned gas mass into the cylinders making VVT variations. To stress the importance of the observation, we keep the intake pressure as a constant controlling the intake throttle. Figure 6 makes the comparison between the air mass given by the reference model $M_{a s p}$ ref, the masses given by the two observers and the mass given by the map, $M_{a s p}^{m a p}$. As $M_{a s p}^{m a p}$ is given by (16), it does not see any change in the quantity of fresh air trapped into the cylinders because of constant pressure and engine speed. On the other hand, the observers catches the variations to provide a reliable estimation. Figure 7 demonstrates the trajectory of the estimated volumetric efficiency $\eta_{\text {map }}\left(N_{e}, P_{\text {man }}\right)+\hat{\delta \eta}$. 


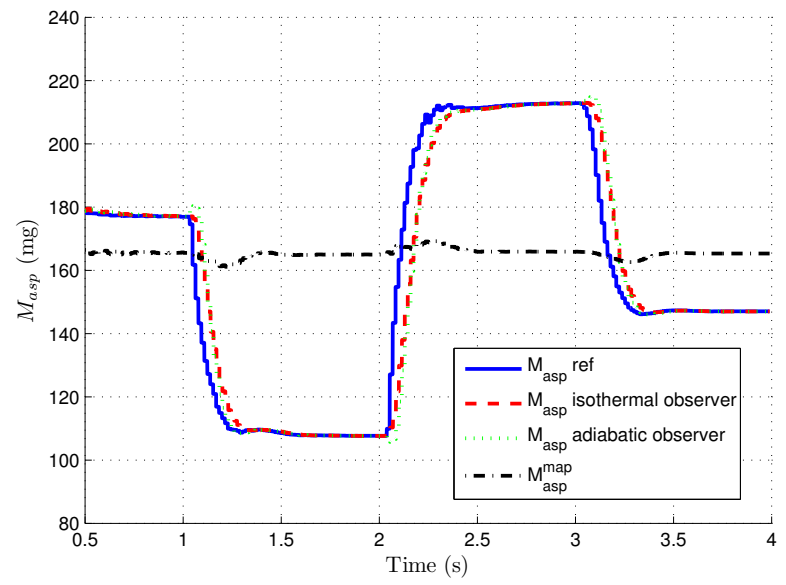

Fig. 6. Air mass aspirated during VVT transients at constant engine speed $(2000 \mathrm{rpm})$ and constant intake pressure $(0.5 \mathrm{bar})$.

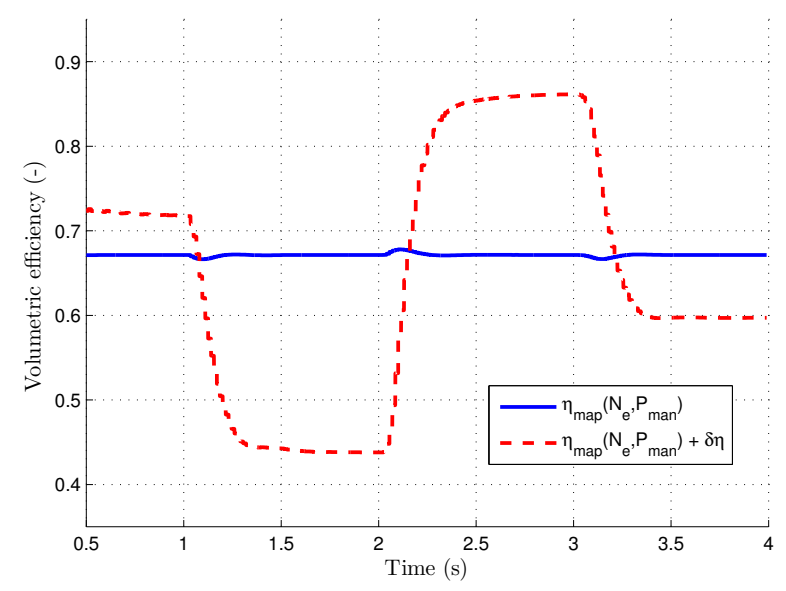

Fig. 7. Volumetric efficiency during at constant engine speed (2000 rpm) and constant intake pressure (0.5 bar).

\section{Vehicle test}

The isothermal observer has been tested with experimental data coming from vehicle. These collected data come from a NEDC cycle. Figure 8 compares the air mass flow measurement, given by the air mass flow sensor, to the air mass estimated, given by the isothermal observer. It shows that the observer well reconstructs the aspirated air mass in the cylinders.

\section{CONCLUSION AND FUTURE DIRECTIONS}

This paper presents two observers for the estimation of the air mass trapped into the cylinders. After presenting the model in Section II, two observers are derived based on different assumptions (in Section III and in Section IV). Experimental results are reported in Section V.

The two observers give approximately the same results. Thus, using the isothermal observer is much easier because there are only two gains to tune. We plan to use this observer in a motion planning control strategy of the air path.

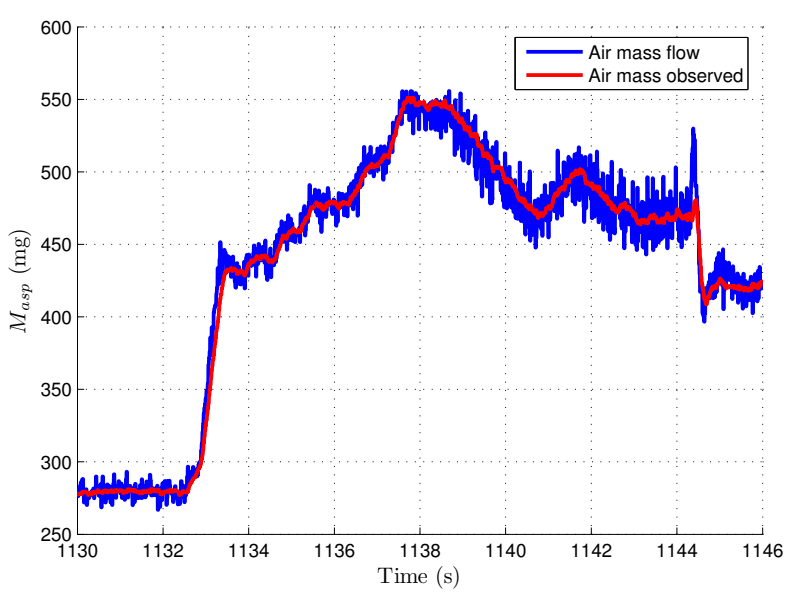

Fig. 8. Experimental vehicle results during a NEDC cycle.

\section{REFERENCES}

[1] P. Andersson. Air Charge Estimation in Turbocharged Spark Ignition Engines. PhD thesis, Linköpings Universitet, dec 2005.

[2] P. Andersson and L. Eriksson. Air-to-cylinder observer on a turbocharged si-engine with wastegate. In Proc. of SAE Conference, number 2001-01-0262, 2001.

[3] J. Chauvin, N. Petit, P. Rouchon, G. Corde, and C. Vigild. Air path estimation on diesel hcci engine. In Proc. of SAE Conference, number 2006-01-1085, 2006.

[4] A. Chevalier, M. Müller, and E. Hendricks. On the validity of mean value engine models during transient operation. In Proc. of SAE Conference, number 2000-01-1261, 2000.

[5] A. Chevalier, C. Vigild, and E. Hendricks. Predicting the port air mass flow of si engines in air/fuel ratio control applications. In Proc. of SAE Conference, number 2000-01-0260, 2000.

[6] L. Eriksson, L. Nielsen, J. Brugard, J. Bergström, F. Pettersson, and P. Andersson. Modeling of a turbocharged si engine. In Proc. of Control Engineering Practice, volume 26, pages 129-137, 2002.

[7] J.W. Grizzle, J.A. Cook, and W.P. Milam. Improved cylinder air charge estimation for transient air fuel ratio control. In Proc. of the American Control Conference, 1994.

[8] L. Guzzella and C.H. Onder. Introduction to Modeling and Control of Internal Combustion Engine Systems. Springer, 2004.

[9] J. Heywood. Internal Combustion Engine Fundamentals. McGrawHill, Inc, 1988.

[10] H. Khalil. Nonlinear Systems. Prentice-Hall, Inc., 1992.

[11] F. Le Berr, M. Miche, G. Le Solliec, F-A. Lafossas, and G. Colin. Modelling of a turbocharged si engine with variable camshaft timing for engine control purposes. In Proc. of SAE Conference, submitted.

[12] B. Lecointe and G. Monnier. Downsizing a gasoline engine using turbocharging with direct injection. In Proc. of SAE Conference, number 2003-01-0542, 2003.

[13] A. Stotsky and I. Kolmanovsky. Application of input estimation techniques to charge estimation and control in automotive engines. In Proc. of Control Engineering Practice, volume 10, pages 1371-1383, 2002. 